\title{
MODEL EVALUASI FORMATIF-SUMATIF TERHADAP MOTIVASI BELAJAR MAHASISWA PADA MATA KULIAH PERENCANAAN PENGAJARAN GEOGRAFI
}

\author{
Susanti Faipri Selegi \\ Program Studi Pendidikan Geografi, Universitas PGRI Palembang \\ e-mail: susantifaipriselegi@gmail.com
}

\begin{abstract}
This study aims to determine the effect of formative-sumative evaluation model on student learning motivation in geography teaching planning course. The type of this research is evaluation research with quantitative approach. Data were obtained through documentation technique and questionnaire. The collected data is processed by multiple linear regression analysis. The results of this study indicate that the summative-formative evaluation obtained an average of 73.8 and 79.4. In the internal motivation aspect, the result of the questionnaire shows that $100 \%$ of students are interested in the subject, interest / willingness to learn, curiosity, enthusiasm to ask, opinion during PBM, enthusiastic to do and complete the task, and enthusiastic in cooperation very well. While the aspect of external motivation shows that $54.8 \%$ of the facilities support the smooth learning process, the atmosphere is conducive, the results are very good, and parents are proud of the value obtained by the students. Learning by using formative-sumative evaluation model has a significant effect on students' learning motivation, as evidenced from the results of multiple linear regression analysis which shows that Fcount $=4,528$ is greater than Ftable $=3.34$, then Ho is rejected. Thus it is known that the formative-sumative evaluation model has a significant effect on students' learning motivation in Geography teaching planning course.
\end{abstract}

Keywords - Evaluation, Formative-Sumatif, Learning

\section{PENDAHULUAN}

$\mathrm{P}$ embelajaran merupakan fenomena yang sedang tumbuh dalam dunia pendidikan, baik dalam pendidikan formal maupun nonformal. Pembelajaran merupakan suatu proses interaksi antara komponen-komponen sistem pembelajaran. Kata pembelajaran ditekankan bahwa kegiatan belajar melalui usaha-usaha yang terencana dalam memanipulasi sumber-sumber belajar agar proses belajar mengajar dapat terlaksana. Pembelajaran sebagai suatu sistem memiliki beberapa komponen, yaitu tujuan pembelajaran, materi pembelajaran, strategi pembelajaran, media pembelajaran, dan evaluasi pembelajaran.

Tujuan pembelajaran merupakan salah satu aspek yang perlu dipertimbangkan dalam merencanakan pembelajaran. Mager dalam Uno (2008:35) memberikan pengertian tujuan pembelajaran sebagai perilaku yang hendak dicapai atau yang dapat dikerjakan oleh siswa pada kondisi dan tingkat kompetensi tertentu. Lebih lanjut, Benyamin S. Bloom dan D. Krathwohl dalam Uno memilah taksonomi pembelajaran dalam tiga kawasan, yaitu kawasan (1) kognitif, (2) afektif, dan (3) psikomotorik. Kawasan kognitif adalah kawasan yang membahas tujuan pembelajaran berkenaan dengan proses mental yang berawal dari tingkat pengetahuan sampai ketingkat yang lebih tinggi yaitu evaluasi. Kawasan afektif adalah satu domain yang berkaitan dengan sikap, nilai-nilai, apresiasi (penghargaan) dan penyesuaian peasaan sosial. Sedangkan kawasan psikomotor mencakup tujuan yang berkaitan dengan keterampilan (skill) yang bersifat manual atau motorik.

Evaluasi sebagai suatu proses menyediakan informasi yang dapat dijadikan sebagai pertimbangan untuk menentukan tujuan yang dicapai, desain, implementasi dan dampak untuk membuat keputusan, pertanggung jawaban, dan meningkatkan pemahaman, sehingga evaluasi diartikan sebagai bahan pertimbangan dalam pengambilan keputusan. Fokus evaluasi adalah kelas, sehingga dampaknya adalah pada kelas. Hasil evaluasi dapat digunakan untuk mendorong pendidik untuk mengajar lebih baik dan mendorong mahasiswa untuk belajar lebih baik.

Hasil evaluasi pendidikan harus dianalisis untuk memperoleh informasi yang akurat untuk perbaikan kualitas pembelajaran.

Perencanaan pembelajaran Geografi sebagai mata kuliah wajib yang harus diikuti mahasiswa pada semester genap bertujuan memberikan bekal pengetahuan mahasiswa dalam bidang pendidikan. Hal tersebut dimaksudkan agar mahasiswa 
memperoleh kompetensi keilmuan yang terencana dan tersistemkan dengan baik. Adapun materi yang diajarkan mulai dari pembahasan silabus, RPP, pengembangan materi ajar, pengembangan media pembelajaran berbasis teknologi, dan evaluasi pembelajaran. Akan tetapi, permasalahan yang ditemukan dalam prosesnya adalah materi yang diajarkan masih ada yang belum memahami dengan baik. Faktor penyebabnya adalah kurang fokusnya mahasiswa pada materi yang diajarkan, kurang kreatif dalam mengembangkan materi yang diberikan, dan kurangnya motivasi diri untuk berkompetisi dengan baik. Oleh karena itu, perlu adanya evaluasi pembelajaran agar tujuan yang hendak dicapai dapat disesuaikan dengan keadaan sebenarnya dan salah satu model evaluasi yang tepat dalam penelitian ini adalah evaluasi model formatif-sumatif.

\section{Evaluasi Pembelajaran}

Stufflebeam \& Shinkfield (1985) dalam Djemari (2012:26) evaluasi didefinisikan sebagai proses untuk memperoleh informasi guna memilih alternatif yang terbaik. Evaluasi juga dapat diartikan sebagai penentu kesesuaian antara hasil yang dicapai dan tujuan yang ingin dicapai. Fokus evaluasi adalah kelas, sehingga dampaknya adalah pada kelas.

Uno (2008:139) mengatakan bahwa mengevaluasi adalah proses mengukur dan memulai. Alat ukur adalah adalah instrumen pengukuran yang konkret. Evaluasi terhadap hasil belajar bertujuan untuk mengetahui ketuntasan dalam menguasai kompetensi dasar. Dari hasil evaluasi tersebut diketahui kompetensi dasar, materi, atau indikator yang belum mencapai ketuntasan. Dengan mengevaluasi hasil belajar, pendidik akan mendapatkan manfaat yang besar untuk melakukan program perbaikan yang tepat. Lebih lanjut, Mertens (2010:49) mengatakan bahwa: "evaluation is an applied inquiry process for collecting and synthesizing evidence that culminates in conclusions about the state of affairs, value, merit, wort, significance, or quality of a program, product, person, policy, proposal, or plan. Evaluasi adalah proses penerapan yang dilakukan untuk mengumpulkan dan mensisntesiskan pembuktian sebagai kesimpulan tentang kualitas program, produk, orang, kebijakan, proposal, atau perencanaan. Pengertian tersebut menunjukkan bahwa evaluasi tidak hanya membahas tentang pendidikan akan tetapi dapat mengakaji seluruh aspek. Adapun standar dalam melakukan evaluasi dijelaskan oleh Mertens (2010:80) : The standars are organized according to five main attributes of evaluations: (a) feasibility-the extent to which the evaluation can be implemented successfully in a specific setting; (b) propriety-how humane, ethical, moral, proper, legal, and professional an evaluation is; (c) accuracy-how dependable, precise, truthful, and trustworthy an evaluation is; (d) utility-how useful and appropriately used an evaluation is; (e) metaevaluation-the extent to which the quality of the evaluation itself is assured and controlled".

Kelima standar memiliki hubungan satu sama lain, yaitu feasibility yang berhubungan dengan standar pelaksanaan evaluasi, propriety yaitu berhubungan dengan etika, moral, dan profesionalitas, accuracy yaitu adanya kejujuran atau bukti yang akurat dalam melaksanakan evaluasi, utility, manfaat yang diperoleh dari evaluasi, dan meta-evaluation kualitas evaluasi dan adanya pengawasan yang baik dalam pelaksanaannya.

Hasil evaluasi dapat digunakan untuk mendorong pendidik untuk mengajar lebih baik dan mendorong peserta didik (mahasiswa) untuk belajar lebih baik. Oleh karena itu, evaluasi memberikan informasi bagi kelas dan pendidik untuk meningkatkan kualitas proses belajar mengajar.

\section{Model Evaluasi Formatif-Sumatif}

Model evaluasi formatif-sumatif adalah model evaluasi yang dibuat oleh Scriven (1967). Scriven mengemukakan bahwa: formative evaluation is to classify evaluation that gathered information for the purpose of improving instruction as the instruction was being given and sumative evaluation is a method to judge the worth of curriculum at the end of the syllabus where the focus is on the outcome" Pernyataan di atas, menjelaskan bahwa evaluasi formatif adalah pengumpulan informasi dengan tujuan memperbaiki pembelajaran yang telah diberikan, sedangkan evaluasi sumatif adalah suatu metode pengambil keputusan diakhir pembelajaran yang memfokuskan pada hasil belajar.

Adapun menurut istilah kata form yang merupakan dasar dari istilah formatif maka evaluasi formatif dimaksudkan untuk mengetahui sejauh mana mahasiswa terbentuk setelah mengikuti suatu program tertentu. evaluasi atau tes formatif diberikan pada akhir setiap program pembelajaran. Tes formatif sering disamakan dengan ulangan harian (kuis) kegiatan yang dilakukan secara periodik untuk mengukur pencapaian kompetensi mahasiswa setelah menyelesaikan satu atau lebih kompetensi yang menjadi target ketercapaian program pembelajaran.

Evaluasi atau tes sumatif dilaksanakan setelah berakhirnya pemberian sekelompok program atau 
sebuah program yang lebih besar. Tes sumatif dapat dilaksanakan dengan ujian akhir semester (UAS). Tes dalam rangka pendidikan digunakan untuk memperoleh bukti tentang taraf keberhasilan proses belajar mengajar. Evaluasi merupakan bagian integral dalam proses belajar mengajar. Tiap pelajaan yang diberikan hendaknya merupakan kebutuhan yang mempunyai tujuan yang jelas, bahan pelajarannya, proses belajar mengajar, maupun evaluasinya (Lodang \& Bara, 122:2012). Lebih lanjut, evaluasi pembelajaran dapat dikategorikan menjadi dua, yaitu formatif dan sumatif. Evaluasi formatif bertujuan untuk memperbaiki proses pembelajaran. Sedangkan evaluasi sumatif bertujuan untuk menetapkan tingkat keberhasilan peserta didik (mahasiswa) (Djemari, 2012:29).

\section{METODOLOGI PENELITIAN}

Jenis penelitian ini dikategorikan sebagai penelitian evaluasi. Penelitian evaluasi merupakan kegiatan penelitian untuk mengumpulkan data, menyajikan informasi yang akurat dan objektif mengenai penerapan model evaluasi formatif-sumatif. Peneliti berusaha menggambarkan model evaluasi formatif-sumatif pada mata kuliah perencanaan pengajaran Geografi. Oleh karena itu, penelitian ini adalah penelitian evaluasi model formatif-sumatif oleh Scriven yang bertujuan untuk memperbaiki proses pembelajaran dan menentukan tingkat keberhasilan mahasiswa.

Pendekatan yang digunakan dalam penelitian ini adalah pendekatan kuantitatif. Pendekatan kuantitatif digunakan sebagai pertimbangan bahwa gejala penelitian ini merupakan proses yang dilakukan melalui kajian terhadap perilaku atau aktifitas para pelaku yang terlibat didalamnya. "Quantitave research usually base their work on the belief that facts and feeling can be separated, that the world is a single reality made up of facts that can be discovered" (Fraenkel and Wallen: 2009:15). Penelitian kuantitatif biasanya didasarkan pada fakta yang dapat ditemukan.

Teknik yang digunakan pada penelitian ini adalah purposive sampling. Purposive sampling bertujuan dilakukan dengan cara mengambil subjek bukan berdasarkan atas strata, random tetapi didasarkan adanya tujuan tertentu dan beberapa pertimbangan (Arikunto, 2010:183). Kriteria yang menjadi sampel dalam penelitian ini yaitu orang yang benar-benar mampu memberikan informasi yang sesuai dengan permasalahan yang terjadi. Oleh karena itu, sampel dalam penelitian ini adalah mahasiswa semester IV yang berjumlah 31 orang pada mata kuliah Perencanaan Pengajaran Geografi.

Teknik analisis data pada penelitian ini menggunakan teknik analisis regresi linear ganda. Analisis regresi digunakan untuk mengetahui pengaruh variabel bebas atau prediktor $(X)$ terhadap variabel terikat atau kriterium (Y). Selain itu, regresi linear ganda pada penelitian ini digunakan untuk mengetahui pengaruh evaluasi formatif $\left(X_{1}\right)$ dan evaluasi sumatif $\left(X_{2}\right)$ terhadap motivasi belajar mahasiswa (Y). Sedangkan untuk pengujian keberartian menggunakan $F_{\text {hitung }}$ dengan taraf kesalahan 0,05. Dengan demikian, koefisien regresi dikatakan berarti jika $F_{\text {hitung }}>F_{\text {tabel }}$ (Sugiyono, 2009:273). Lebih lanjut, Riduwan (2010:255) mengemukakan untuk menentukan aturan pengambilan keputusan atau kriteria uji signifikansi korelasi ganda kaidah yang digunakan jika $F_{\text {hitung }}>$ $F_{\text {tabel, }}$ maka tolak Ho (signifikan) dan jika $F_{\text {hitung }}<F_{\text {tabel }}$ tolak $\mathrm{Ha}$ (tidak signifikan), sedangkan untuk

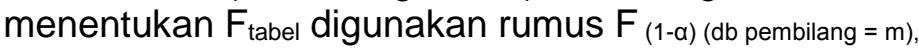
$(\mathrm{db}$ penyebut $=\mathrm{n}-\mathrm{m}-1)$ dengan taraf signifikansi 0,05 .

\section{HASIL DAN PEMBAHASAN}

Pada penelitian ini evaluasi formatif - sumatif diperoleh dengan menggunakan teknik dokumentasi, sehingga peneliti hanya mengelolah data berdasarkan data yang sudah ada. Adapun hasil yang diperoleh rata-rata evaluasi formatif adalah 73,8 dan 79,4 pada evaluasi sumatif. Hasil tersebut menunjukkan adanya peningkatan nilai yang diperoleh mahasiswa pada evaluasi sumatif.

Kuesioner/angket yang digunakan pada penelitian ini terdiri dari dua aspek yaitu aspek motivasi internal dan aspek motivasi eksternal. Peneliti menggunakan instrumen kuesioner/angket yang terdiri dari 15 pertanyaan/pernyataan dan 31 responden, dengan ketegori 5=sangat baik, 4=baik, 3=cukup, 2=kurang baik, 1=tidak baik. Pada hasil item nomor 1, 2, 3, 4, 5, 6, 7, 8, 11 masing-masing diperoleh jumlah 155 atau $100 \%$ mahasiswa yang menjawab ketertarikan terhadap mata kuliah, adanya minat/keinginan untuk belajar, adanya rasa ingin tahu, antusias bertanya, berpendapat selama PBM berlangsung, antusias mengerjakan dan menyelesaikan tugas, dan antusias dalam bekerjasama dengan sangat baik.

Pada item nomor 9 berjumlah 153 atau 93,5\% mahasiswa menjawab menyelesaikan tugas tepat waktu dengan sangat baik, item nomor 10 berjumlah 149 atau $80,6 \%$ mahasiswa menjawab sangat senang bisa menyelesaikan tugas tepat waktu dengan sangat baik, item nomor 13 berjumlah 141 atau $54,8 \%$ menjawab fasilitas yang lengkap mendukung 
kelancaran proses pembelajaran dengan sangat baik, item nomor 12 berjumlah 138 atau 45,2\% mahasiswa menjawab suasana lingkungan tempat belajar kondusif dengan sangat baik, item nomor 14 berjumlah 129 atau 16,1\% mahasiswa menjawab mendapatkan hasil (nilai) sangat baik dengan sangat baik, dan item nomor 15 berjumlah 127 atau 9,6\% mahasiswa menjawab orang tua bangga dengan nilai yang diperoleh dengan sangat baik.

Penelitian ini menggunakan uji persyarat analisis yaitu uji normalitas data, uji linearitas data, dan uji hipotesis. Dari hasil analisis uji normalitas data kolmogorov-Smirnov menunjukkan hasil variabel formatif $\left(X_{1}\right)=0,430$, variabel sumatif $\left(X_{2}\right)=0,263$, dan variabel motivasi belajar $(Y)=0,518$. Dengan demikian hasil uji normalitas $\left(X_{1=0,430}>0,05\right),\left(X_{2=0,263}\right.$ $>0,05)$, dan $\left(\mathrm{Y}_{=0,518}>0,05\right)$ maka distribusinya dinyatakan normal.

Pada uji linearitas diketahui linearitas variabel motivasi belajar $(Y)$ atas formatif $\left(X_{1}\right)=2,890$ dan variabel motivasi belajar $(\mathrm{Y})$ atas sumatif $\left(\mathrm{X}_{2}\right)=3,906$. Berdasarkan hasil tersebut nilai signifikansi dari nilai $F$ pada lajur deviation from linearity lebih besar dari 0,05 (> 0,05), maka dapat disimpulkan bahwa hubungan antar masing-masing variabel formatif $\left(X_{1}\right)$, sumatif $\left(\mathrm{X}_{2}\right)$, dan motivasi belajar $(\mathrm{Y})$ adalah linear. Dengan demikian, uji linearitas terpenuhi.

Uji hipotesis dalam penelitian ini adalah teknik analisis regresi linear ganda. Analisis regresi digunakan untuk mengetahui pengaruh variabel bebas atau prediktor $(X)$ terhadap variabel terikat atau kriterium (Y). Regresi linear ganda pada penelitian ini digunakan untuk mengetahui pengaruh evaluasi formatif $\left(X_{1}\right)$ dan evaluasi sumatif $\left(X_{2}\right)$ terhadap motivasi belajar mahasiswa $(\mathrm{Y})$. Berdasarkan hasil analisis dengan alpha $(\alpha=5 \%)$ dan $\mathrm{dk}=\mathrm{N}-\mathrm{A}-1$ menunjukkan $F_{\text {hitung }}=4,528$ dan $F_{\text {tabel }}=3,34$, sehingga $F_{\text {hitung }}>F_{\text {tabel }}$ maka Ho ditolak. Dengan demikian model evaluasi formatif-sumatif berpengaruh signifikan terhadap motivasi belajar mahasiswa pada mata kuliah perencanaan pengajaran Geografi.

Belajar bukan suatu tujuan atau hasil tetapi merupakan suatu proses untuk mencapai tujuan dan belajar bukan hanya meningkatkan, akan tetapi lebih luas dari itu yakni mengalami (Hamalik, 2010:36). Untuk memaksimalkan proses belajar dan pembelajaran maka diperlukan evaluasi. Evaluasi formatif bertujuan untuk memperbaiki proses pembelajaran. Sedangkan evaluasi sumatif bertujuan untuk menetapkan tingkat keberhasilan peserta didik (mahasiswa) (Djemari, 2012:29).
Penelitian pada evaluasi formatif-sumatif menunjukkan bahwa hasil yang diperoleh pada evaluasi formatif (UTS) memberikan pengaruh pada keberhasilan evaluasi sumatif (UAS). Hal tersebut terlihat dari meningkatnya nilai yang diperoleh mahasiswa pada evaluasi formatif dengan rata-rata 73,8 dan meningkat pada evaluasi sumatif pada ratarata 79,4. Meskipun peningkatan tidak terlalu besar setidaknya mahasiswa mengalami perbaikan dalam proses pembelajarannya. Purwanto (2010:102) mengemukakan bahwa faktor-faktor yang mempengaruhi berhasil tidaknya belajar adalah faktor kematangan, kecerdasan, latihan, motivasi, keadaan rumah tangga, guru dan cara atau metode yang digunakan dalam mengajar, alat-alat yang digunakan, lingkungan dan motivasi sosial.

Variabel motivasi belajar mahasiswa $(Y)$ yang diberikan kepada responden dengan menggunakan instrumen kuesioner/angket memperlihatkan bahwa secara internal mahasiswa mempunyai ketertarikan, minat, rasa ingin tau, antusiasme dalam pelaksanaan pembelajaran, dan penyelesaikan tugas pada mata kuliah perencanaan pengajaran Geografi. Hal ini senada dengan apa yang dikemukakan Salim (2013:395) bahwa motivasi adalah dorongan yang timbul pada diri seseorang sacara sadar atau tidak untuk melakukan suatu tindakan dengan tujuan tertentu. Sementara itu, motivasi eksternal berdasarkan kuesioner/angket memperlihatkan bahwa fasilitas mendukung kelancaran proses pembelajaran, suasana yang kondusif, hasil yang sangat baik, dan orang tua bangga dengan nilai yang diperoleh mahasiswa. Hasil tersebut diperkuat dengan pendapat Hamalik (2011:57) yang mengartikan pembelajaran adalah suatu kombinasi yang tersusun meliputi unsur-unsur manusiawi, material (buku, papan tulis, kapur atau spidol, fotografi), fasilitas, perlengkapan dan prosedur (belajar, jadwal dan metode informasi) yang saling mempengaruhi mencapai tujuan pembelajaran.

Menurut Scriven (1967) evaluasi formatif adalah pengumpulan informasi dengan tujuan memperbaiki pembelajaran yang telah diberikan, sedangkan evaluasi sumatif adalah suatu metode pengambil keputusan diakhir pembelajaran yang memfokuskan pada hasil belajar. Keputusan dalam penelitian ini dapat dilihat berdasarkan hasil analisis regresi linear berganda. Pada tabel 4.1 dapat disimpulkan bahwa variabel evaluasi formatif $\left(X_{1}\right)$, sumatif $\left(X_{2}\right)$, dan motivasi belajar mahasiswa $(Y)$ dengan alpha $(\alpha=$ $5 \%$ ) dan $\mathrm{dk}=\mathrm{N}-\mathrm{A}-1$ menunjukkan bahwa $\mathrm{F}_{\text {hitung }}=$ 4,528 lebih besar dari $F_{\text {tabel }}=3,34$, maka Ho ditolak. Dengan demikian diketahui model evaluasi formatif- 
sumatif berpengaruh signifikan terhadap motivasi belajar mahasiswa pada mata kuliah perencanaan pengajaran Geografi.

\section{SIMPULAN DAN SARAN \\ Simpulan}

Berdasarkan hasil penelitian dan pembahasan pada bab sebelumnya, dapat disimpulkan sebagai berikut. (1) Pada evaluasi formatif-sumatif diperoleh rata-rata 73,8 dan 79,4 . Hasil tersebut menunjukkan adanya peningkatan nilai yang diperoleh mahasiswa pada evaluasi sumatif. Adapun motivasi belajar mahasiswa pada aspek motivasi internal hasil kuesioner/angketnya menunjukkan $100 \%$ mahasiswa tertarik terhadap mata kuliah, adanya minat/keinginan untuk belajar, adanya rasa ingin tahu, antusias bertanya, berpendapat selama PBM berlangsung, antusias mengerjakan dan menyelesaikan tugas, dan antusias dalam bekerjasama dengan sangat baik. Sedangkan aspek motivasi eksternal menunjukkan bahwa $54,8 \%$ fasilitas mendukung kelancaran proses pembelajaran, suasana yang kondusif, hasil yang sangat baik, dan orang tua bangga dengan nilai yang diperoleh mahasiswa, (2) Pembelajaran dengan menggunakan model evaluasi formatif-sumatif berpengaruh signifikan terhadap motivasi belajar mahasiswa, yang dibuktikan dari hasil analisis regresi linear berganda yang menunjukkan bahwa $F_{\text {hitung }}=$ 4,528 lebih besar dari $F_{\text {tabel }}=3,34$, maka Ho ditolak. Dengan demikian diketahui model evaluasi formatifsumatif berpengaruh signifikan terhadap motivasi belajar mahasiswa pada mata kuliah perencanaan pengajaran Geografi.

\section{Saran}

Berdasarkan hasil kesimpulan di atas, peneliti memberikan saran sebagai berikut.

1. Tenaga Pendidik

Perlu adanya peningkatan kualitas pembelajaran yang lebih mendukung mahasiswa pada mengembangkan bakat, minat, kreativitas, serta perlu dilakukan monitoring evaluasi agar perkembangan kemampuan mahasiswa dapat di pantau dengan baik. 2. Mahasiswa

Belajar giat dengan keinginan untuk sukses akan mendorong diri untuk lebih proaktif dalam perkuliahannya, sehingga hasil yang diperoleh dapat lebih maksimal.

\section{Perguruan Tinggi}

Perguruan tinggi hendaknya memperhatikan pengembangan keilmuan bagi seluruh civitas akademika sehingga dapat terus berinovasi seiring perkembangan zaman.

\section{DAFTAR PUSTAKA}

1. Arikunto, Suharsimi. 2010. Prosedur Penelitian Suatu Pendekatan Praktik. Jakarta : Rineka Cipta.

2. Ahmadi, Abu. 2009. Psikologin Sosial. Jakarta: Rineka Cipta.

3. Dimyati dan Mudjiono. 2009. Belajar dan Pembelajaran. Jakarta: Rineka Cipta.

4. Jamarah, syaiful Bahri. 2010. Strategi Belajar Mengajar. Jakarta: Rineka Cipta.

5. Ghani, A. Abdul Rahman. 2008. Pengaruh tes formatif dan kemandirian belajar terhadap hasil belajar ekonomi siswa SMA. Jurnal Penelitian dan Evaluasi Pendidikan, nomor 2, tahun XII.

6. Hamalik, Oemar. 2010. Proses Belajar Mengajar. Jakarta: Bumi Aksara.

7. 2011. Kurikulum dan Pembelajaran. Jakarta: Bumi Aksara

8. Lodang, Hamka \& Bara, Nur Afni Suraya. 2012. Analisis kesesuaian antara instrumen evaluasi formatif dengan tujuan kognitif pembelajaran Biologi di SMP Watansoppeng. Jurnal Bionature, Volume 13, Nomor 2, Oktober.

9. Nashar. 2004. Peranan Motivasi dan Kemampuan Awal dalam Kegiatan Pembelajaran. Jakarta: Delia Press.

10. Purwanto, Ngalim. 2010. Psikologi Pendidikan. Bandung: Remadja Rosdakarya.

11. Sardiman . 2012. Interaksi dan Motivasi Belajar Mengajar. Jakarta: PT RajaGrafindo.

12. Slameto. 2010. Belajar dan Faktor-Faktor yang Mempengaruhinya. Jakarta: Rineka Cipta.

13. Salim, Yulius. 2013. Kamus Lengkap Bahasa Indonesia. Jakarta: Widyatamma Pressindo.

14. Suryabrata, Sumadi. 2012. Psikologi Pendidikan. Jakarta: rajawali Pers.

15. Riduwan, Dr., M.B.A. 2010. Dasar-dasar Statistika. Bandung: Alfabeta.

16. Trianto, 2009. Mendesain Model Pembelajaran Inovatif/Progresif. Jakarta: Kencana Prenada Medika Group.

17. Wardiyatmoko, K. 2004. Gografi SMA Kelas X. Jakarta: Erlangga. 